\title{
Effect of Dexmedetomidine and Remifentanil on Renal Function in Patients Undergoing Bariatric Surgery
}

\section{Antonio Carlos Meinberg1*, João Pedro Raduan Meinberg², Nathália Simões Artíbale², Pedro Thadeu Galvão Vianna3 ${ }^{3}$, Idiberto José Zotarelli Filhoº,4,5,6}

${ }^{1}$ Discipline of Anesthesiology, School of Medicine of São José do Rio Preto, FAMERP, São José do Rio Preto/SP, Brazil

${ }^{2}$ FACERES Medical School of São José do Rio Preto/SP, Brazil

${ }^{3}$ Disciplina de Anestesiologia, Faculdade de Medicina de Botucatu, Universidade Estadual Paulista, São José do Rio Preto/SP, Brasil ${ }^{4}$ Department of Physics (Molecular Biophysics), State University of São Paulo, IBILCE-UNESP, São José do Rio Preto/SP, Brazil ${ }^{5}$ Zotarelli-Filho Scientific Work, São José do Rio Preto/SP, Brazil

${ }^{6}$ Bentham Science Ambassador, São José do Rio Preto/SP, Brazil

Email: *scientific@institutodomingobraile.com.br

How to cite this paper: Meinberg, A.C. Meinberg, J.P.R., Artíbale, N.S., Vianna, P.T.G. and Filho, I.J.Z. (2020) Effect of Dexmedetomidine and Remifentanil on Renal Function in Patients Undergoing Bariatric Surgery. Open Journal of Anesthesiology, 10, 120-133.

https://doi.org/10.4236/ojanes.2020.104011

Received: January 27, 2020

Accepted: April 11, 2020

Published: April 14, 2020

Copyright $\odot 2020$ by author(s) and Scientific Research Publishing Inc. This work is licensed under the Creative Commons Attribution International License (CC BY 4.0).

http://creativecommons.org/licenses/by/4.0/

\section{(c) (i) Open Access}

\begin{abstract}
Background and Objectives: In anesthesia for bariatric surgery, alterations occur in several organs, including the kidney. The objective of this study was to compare the effect of dexmedetomidine and remifentanil on the renal function of morbidly obese patients submitted to bariatric surgery. Methods: Sixty-one patients were studied prospectively and divided randomly into two groups: remifentanil (R) and dexmedetomidine (D). Renal function was evaluated in three phases: before anesthesia (M0), after anesthetic induction (M1) and after surgical incision (M2). Plasma concentrations were determined for glucose, antidiuretic hormone, creatinine, urea, sodium, potassium and osmolarity and urinary concentrations for creatinine, urea, sodium, potassium and osmolarity. Results: Significant differences were found between groups for potassium at M1 $(\mathrm{p}<0.05)$, osmolarity at M2 $(\mathrm{p}<0.05)$ and glucose at M1 and M2 ( $p<0.01$ and $\mathrm{p}<0.001$, respectively). Urinary volume was significantly different between groups at M2 $(p<0.001)$. In group $R$ there was a drop in mean clearance values from M0 to M1 for sodium, potassium, urea, creatinine and osmolarity; in group D the mean clearance values of sodium and osmolarity rose while values for potassium, creatinine and urea fell. There was a reduction in both groups for all variables between moments M1 and M2 and from M0 to M2. Conclusions: In both groups, the clearance values fell from moments M0 to M2. This result indicates that renal function of obese patients submitted to bariatric surgery presented a physiological response compatible
\end{abstract}


with the effect of anesthetic-surgical stress. In the group D, creatinine and sodium clearances were elevated at M1. Urinary volume was greater at M2. These results are suggestive of better preservation of renal function.

\section{Keywords}

Renal Function, Bariatric Surgery, Dexmedetomidine, Remifentanil

\section{Introduction}

Among the various medications used in anesthesia, most of these are fat-soluble. In obese patients, the distribution of anesthetics occurs in the fatty peripheral compartment, which is increased, delaying recovery from anesthesia [1]. Based on this information, the choice of substances with faster recovery, less production of active metabolites and predictable elimination are recommended for anesthesia in bariatric surgeries [2]. Following this principle, remifentanil, with its characteristic extrahepatic metabolism (plasma and tissue esterases), which guarantees rapid recovery, even after prolonged infusion, and has an elimination half-life of 9 to 10 minutes, has a good indication for anesthesia in patients obese [3] [4] [5]. Breen et al. [6] studied the effect of remifentanil infused over 72 hours in patients with renal failure, admitted to the intensive care unit, with no increase in the incidence of adverse effects and prolonged pharmacodynamic effects of the drug.

Several techniques have been used in the anesthesia of the morbidly obese. In our Anesthesiology Service, dexmedetomidine in continuous infusion for anesthesia in obese patients has been successfully used since 2002. This drug is an alpha-2 agonist with a great affinity for the receptor (1620:1) [7] reduces blood pressure and heart rate, has an analgesic, hypnotic and sedative effect [8], with the peculiarity of not causing respiratory depression, even in doses high [9]. Another advantage is its ability to present synergism with most inhaled anesthetics [10] and opioids [11], reducing the number of drugs in anesthesia.

Experimental studies show that this drug acts on renal function, reducing the release of antidiuretic hormone and, consequently, increasing diuresis (8). In addition, results of a clinical study showed that this drug acts not only in distal renal tubules but also in the proximal portion of the nephron, improving renal performance in the postoperative period of patients undergoing thoracotomy [11]. Sudré et al. [12], in a comparative study between dexmedetomidine and remifentanil, used as adjuvants to the anesthetic technique (general/epidural) in bariatric surgery, involving 92 morbidly obese patients, evaluated anesthetic recovery and postoperative analgesia. This study showed the superiority of the remifentanil group over dexmedetomidine in terms of anesthetic recovery and postoperative analgesia.

Considering that obese individuals with renal failure, in addition to representing 
an additional challenge for the anesthesiologist, may show improvement in this function after bariatric surgery [13] [14] [15] [16], the aim of the present study was to comparatively study the effect of dexmedetomidine or remifentanil on the renal function of morbidly obese patients undergoing bariatric surgery.

\section{Methods}

\subsection{Study Design}

After approval by the institutional ethics committee and signing the informed consent form by the patients, 61 patients with morbid obesity who underwent bariatric surgery. Only patients classified by the American Society of Anesthesiology (ASA) [17] as ASA III were investigated, and this criterion defined the sample size due to the existing number of patients with this profile. Exclusion criteria included the age group under 18 and over 63 years, patients with systemic infection, heart, liver and kidney failure, and use of psychotropics.

The study was double-blind and two anesthesiologists participated in the operating room. The anesthesiologist who collected the research data was not aware of the type of medication to be used, while the other was tasked with preparing the drawn medication and infusing it.

\subsection{Settings}

The study took place in Base Hospital and Famerp of São José do Rio Preto, São Paulo, Brazil. All data were strictly kept confidential.

\subsection{Groups}

Patients were randomly divided into two groups: $\mathrm{R}$ (remifentanil) and $\mathrm{D}$ (dexmedetomidine). All individuals received midazolam (Cristália, Itapira, SP) (5 mg), after venoclysis in the operating room. In group R, remifentanil (GSK, Rio de Janeiro) $\left(0.1 \mu \mathrm{g} \cdot \mathrm{kg}^{-1} \cdot \mathrm{min}^{-1}\right)$ was used, being infused continuously by means of a Samtronic 680 infusion pump (Samtronic, São Paulo, SP) throughout the period of the surgical procedure. After $10 \mathrm{~min}$ of infusion of this anesthetic, the patient's orotracheal intubation (IoT) was performed after administration of propofol (Cristália, Itapira, SP) until BIS 40 and succinylcholine (União Química, Embu-Guaçu, SP) (1.2 mg/kg).

In group D, dexmedetomidine (Hospira Inc., Rocky Mount, North Carolina, USA) was used in continuous infusion with an infusion pump. During the initial 10 minutes, this drug was infused in the amount of $1 \mu \mathrm{g} \cdot \mathrm{kg}^{-1}$. Then, the patient was intubated after administration of propofol until BIS 40 and succinylcholine $(1.2 \mathrm{mg} / \mathrm{kg})$.

\subsection{Interventions}

After IoT, anesthesia was maintained with remifentanil $\left(0.1 \mu \mathrm{g} \cdot \mathrm{kg}^{-1} \cdot \mathrm{min}^{-1}\right)$ or dexmedetomidine $\left(0.5 \mu \mathrm{g} \cdot \mathrm{kg}^{-1} \cdot \mathrm{h}^{-1}\right), 50 \%$ nitrous oxide (White Martins), $50 \%$ 
oxygen and isoflurane (Farmasa, São Paulo, SP) in the concentration necessary to maintain BIS close to 50 .

Hydration was performed based on the ideal weight. After approximately $10 \mathrm{~h}$ of fasting, water replacement was performed with $2 \mathrm{~mL} \cdot \mathrm{kg}^{-1} \cdot \mathrm{h}^{-1}$ of fasting with sodium lactate Ringer's solution (JP Indústria Farmacêutica, Ribeirão Preto, SP) until the beginning of the surgery. After the surgical procedure was started, the replacement was performed with the same $10 \mathrm{~mL} \cdot \mathrm{kg}^{-1} \cdot \mathrm{h}^{-1}$ solution.

For the dosages of all medications, the actual weight was used in both groups. After IoT, all patients were maintained on mechanical ventilation, using a Datex Aestiva/5 7100 ventilator (Datex-Ohmeda Inc., Madison, Wisconsin, USA), with a tidal volume of $10 \mathrm{~mL} \cdot \mathrm{kg}^{-1}$ of the ideal weight [18], respiratory rate of 12 per $\mathrm{min}$, FIO2 of $50 \%$, PEEP of 5 to $8 \mathrm{~cm}$ of $\mathrm{H}_{2} \mathrm{O}$ [19]. During the surgical procedure, atracurium bromide (Cristália, Itapira, SP) was used to maintain muscle relaxation $\left(0.3 \mathrm{mg} \cdot \mathrm{kg}^{-1} \cdot \mathrm{h}^{-1}\right)$. The degree of relaxation was assessed using a TOF-Watch monitor (Organon Teknika BV, Boseindis, Netherlands).

The evaluation of renal function in patients undergoing bariatric surgery was carried out in three phases: before anesthesia (M0), after anesthetic induction (M1-the period between induction of anesthesia and beginning of surgery) and after surgical incision (M2-up to $1 \mathrm{~h}$ of surgery).

After placing the bladder catheter, residual urine was eliminated, and diuresis $\left(\mathrm{mL} \cdot \mathrm{min}^{-1}\right)$ was evaluated for at least $30 \mathrm{~min}$. After 10 to $15 \mathrm{~min}$ of evaluation of diuresis, $10 \mathrm{~mL}$ of blood was taken for blood glucose, antidiuretic hormone (vasopressin), creatinine, urea, sodium, potassium, and osmolarity. Prior to dosing, centrifugation was performed using an Excelsa Fanem centrifuge (Guarulhos, SP). Urine samples were sent for measurement of creatinine, urea, sodium, potassium, and osmolarity. These procedures were carried out in the three phases.

The glucose and urea measurements were determined by the colorimetric enzymatic method; creatinine by the Jaffé reaction and sodium and potassium by the selective electrode method. In determining urinary and plasma osmolarity, a Laboratory Model 3L osmometer (Natick, Massachusetts, USA) was used, which is based on the method of decreasing the freezing point, using $0.2 \mathrm{~mL}$ of plasma or urine and expressing the result in $\mathrm{mOsm} / \mathrm{kg}$ of $\mathrm{H}_{2} \mathrm{O}^{-1}$.

For plasmatic measurement of vasopressin, $5 \mathrm{~mL}$ of venous blood was collected in tubes with 2 drops of heparin, centrifuged in an Eppendorf 580R refrigerated centrifuge (São Paulo, SP) at $4^{\circ} \mathrm{C}$, and plasma was separated and kept frozen at $-20^{\circ} \mathrm{C}$, until the measurement of vasopressin. The technique used was radioimmunoassay, using the vasopressin arginine kit, RIA method from Geneses (Webster, Texas, USA) and Wizard Automatic Gama Counter 1470 equipment (Meriden, Connecticut, USA).

\subsection{Statistical Analysis}

In the statistical analysis of quantitative variables (age, weight, height, and BMI) that showed normal distribution and homogeneity of variances, Student's t-test 
was used. For the gender variable, the Chi-square test [20] was used. When comparing variables related to renal function, the Student's t-test and Mood's test (heterogeneity of variances) were used [20]. The level of significance adopted was $\mathrm{p}<0.05$.

\section{Results}

In the present study, the selected patients presented aged between 19 and 63 years (35.6 \pm 9.9 years) were prospectively studied, being 17 (27.8\%) male and 44 (72.2\%) female, regardless of race Analyzing the results for the variables age, weight, height, and BMI, it was found that there was no significant difference between the groups (Table 1). As for sex, in group $\mathrm{R}$ there were $33.4 \%$ male and $66.6 \%$ female, and in group D $22.6 \%$ male and $77.4 \%$ female.

In the evaluation of renal function, the mean values of plasma concentration of sodium, creatinine, urea and antidiuretic hormone before anesthesia (OM), after anesthetic induction (M1) and after surgical incision (M2), did not show differences between groups $\mathrm{R}$ and $\mathrm{D}$ (Table 2). Significant differences were found between groups for potassium in M1 ( $<<0.05)$, osmolarity in M2 $(p<0.05)$ and glucose in M1 and M2 ( $<<0.01$ and $\mathrm{p}<0.001$, respectively) (Table 2).

Regarding the mean values of urinary concentration of sodium, potassium, creatinine, urea, and osmolarity, there were no differences between groups $\mathrm{R}$ and $\mathrm{D}$ at moments M0 and M1 (Table 3). In M2, significant differences were observed between the groups for potassium and urea $(\mathrm{p}<0.05)$, and sodium, creatinine, and osmolarity ( $\mathrm{p}<0.01$ ) (Table 3$)$. The urine volume was significantly different between the groups only at time M2 (p < 0.001) (Table 3$)$.

In the mean values of sodium clearance, no significant differences were observed between groups in M0, M1, and M2 (Table 4). At M1 and M2, the differences were significant between the groups for potassium $(\mathrm{p}<0.001$ and $\mathrm{p}<$ 0.05 , respectively) (Table 4). For creatinine, there was a significant difference between groups at M1 ( $<$ 0.05) (Table 4). In M1 and M2, the differences were significant between groups for urea ( $\mathrm{p}<0.01$ and $\mathrm{p}<0.05$, respectively) (Table 4 ). In the values of osmolar clearances and free water and fractional sodium excretion, there was no significant difference between groups at all times (Table 4).

There was no acute renal failure in any patient in the present study.

Table 1. Mean and standard deviation related to the groups' characterization variables.

\begin{tabular}{cccc}
\hline & \multicolumn{3}{c}{ Groups } \\
Variables & $\mathrm{R}$ & $\mathrm{D}$ & \\
\cline { 2 - 4 } & $34.8 \pm 9.7$ & $36.4 \pm 10.1$ & 0.54 \\
Age (years) & $138.7 \pm 23.6$ & $129.9 \pm 20.9$ & 0.13 \\
Weight $(\mathrm{kg})$ & $1.7 \pm 0.1$ & $1.6 \pm 0.1$ & 0.32 \\
High $(\mathrm{m})$ & $49.0 \pm 6.84$ & $47.5 \pm 6.4$ & 0.36
\end{tabular}

Groups: R (remifentanil), D (dexmedetomidine). 
Table 2. Plasma concentration of sodium, potassium, creatinine, urea, osmolarity, antidiuretic hormone and glucose in patients undergoing bariatric surgery in groups $\mathrm{R}$ (remifentanil, $\mathrm{n}=30$ ) and $\mathrm{D}$ (dexmedetomidine, $\mathrm{n}=31$ ) before anesthesia $(\mathrm{MO})$, after anesthetic induction (M1) and after surgical incision (M2).

\begin{tabular}{|c|c|c|c|}
\hline Group & M0 & M1 & M2 \\
\hline & \multicolumn{3}{|c|}{ Sodium $(\mathrm{mEq} / \mathrm{L})$} \\
\hline $\mathrm{R}$ & $141.4 \pm 3.5$ & $140.8 \pm 4.0$ & $139.9 \pm 4.7$ \\
\hline \multirow[t]{2}{*}{$\mathrm{D}$} & $141.1 \pm 3.7$ & $140.1 \pm 3.7$ & $139.8 \pm 4.6$ \\
\hline & \multicolumn{3}{|c|}{ Potassium (mEq/L) } \\
\hline $\mathrm{R}$ & $4.1 \pm 0.4$ & ${ }^{\star} 4.1 \pm 0.4$ & $4.0 \pm 0.6$ \\
\hline \multirow[t]{2}{*}{$\mathrm{D}$} & $4.1 \pm 0.3$ & ${ }^{\star} 4.3 \pm 0.4$ & $4.2 \pm 0.4$ \\
\hline & \multicolumn{3}{|c|}{ Creatinine (mg/dL) } \\
\hline $\mathrm{R}$ & $0.7 \pm 0.2$ & $0.7 \pm 0.2$ & $0.7 \pm 0.2$ \\
\hline \multirow[t]{2}{*}{$\mathrm{D}$} & $0.7 \pm 0.2$ & $0.7 \pm 0.2$ & $0.7 \pm 0.2$ \\
\hline & \multicolumn{3}{|c|}{ Urea $(\mathrm{mg} / \mathrm{dL})$} \\
\hline $\mathrm{R}$ & $28.6 \pm 7.0$ & $27.3 \pm 7.5$ & $27.7 \pm 6.9$ \\
\hline \multirow[t]{2}{*}{$\mathrm{D}$} & $26.2 \pm 7.8$ & $25.5 \pm 7.2$ & $25.4 \pm 6.4$ \\
\hline & \multicolumn{3}{|c|}{ Osmolarity $(\mathrm{mOsmol} / \mathrm{L})^{1}$} \\
\hline $\mathrm{R}$ & $272.7 \pm 11.9$ & $272.1 \pm 17.4$ & $\star 273.7 \pm 7.4$ \\
\hline \multirow[t]{2}{*}{$\mathrm{D}$} & $282.5 \pm 14.7$ & $278.3 \pm 14.1$ & $\star 282.9 \pm 12.7$ \\
\hline & \multicolumn{3}{|c|}{ Antidiuretic hormone $(\mathrm{pg} / \mathrm{mL})^{2}$} \\
\hline $\mathrm{R}$ & $35.9 \pm 14.3$ & $32.9 \pm 15.7$ & $26.2 \pm 18.9$ \\
\hline \multirow[t]{2}{*}{$\mathrm{D}$} & $39.1 \pm 17.2$ & $38.5 \pm 15.4$ & $35.8 \pm 15.9$ \\
\hline & \multicolumn{3}{|c|}{ Glucose (mg/dL) } \\
\hline $\mathrm{R}$ & $93.1 \pm 37.7$ & $* * 99.3 \pm 31.2$ & $* * * 100.3 \pm 30.0$ \\
\hline $\mathrm{D}$ & $105.0 \pm 53.4$ & $* * 136.5 \pm 53.4$ & $\star \star * \star 155.1 \pm 59.2$ \\
\hline
\end{tabular}

${ }^{*} \mathrm{p}<0.05 ;{ }^{* *} \mathrm{p}<0.01 ;{ }^{* * *} \mathrm{p}<0.001 .{ }^{\mathrm{I} G}$ Goup R (remifentanil, $\mathrm{n}=14$ ), D (dexmedetomidina, $\mathrm{n}=15$ ); ${ }^{2}$ Group R (remifentanil, $\mathrm{n}=13$ ), $\mathrm{D}$ (dexmedetomidina, $\mathrm{n}=14$ ).

Table 3. Urinary concentration of sodium, potassium, creatinine, urea, osmolarity and urinary volume of patients undergoing bariatric surgery in groups $\mathrm{R}$ (remifentanil, $\mathrm{n}=30$ ) and $\mathrm{D}$ (dexmedetomidine, $\mathrm{n}=31$ ) before anesthesia $(\mathrm{MO})$, after anesthetic induction (M1) and after surgical incision (M2).

\begin{tabular}{cccc}
\hline Group & M0 & M1 & M2 \\
\hline & & Sodium $(\mathrm{mEq} / \mathrm{L})^{1}$ & \\
$\mathrm{R}$ & $161.0 \pm 63.6$ & $174.9 \pm 108.6$ & $* \star 193.1 \pm 158.3$ \\
$\mathrm{D}$ & $161.0 \pm 84.6$ & $143.5 \pm 117.8$ & $* * 91.8 \pm 75.3$ \\
\hline & & Potassium $(\mathrm{mEq} / \mathrm{L})$ & \\
$\mathrm{R}$ & $33.4 \pm 19.0$ & $29.5 \pm 16.7$ & $* 39.9 \pm 20.6$ \\
$\mathrm{D}$ & $44.6 \pm 31.0$ & $34.1 \pm 35.5$ & $\star 26.5 \pm 24.2$ \\
\hline
\end{tabular}




\section{Continued}

\begin{tabular}{|c|c|c|c|}
\hline & \multicolumn{3}{|c|}{ Creatinine (mg/dL) } \\
\hline $\mathrm{R}$ & $119.6 \pm 86.4$ & $93.6 \pm 68.9$ & ${ }^{* *} 118.5 \pm 73.9$ \\
\hline \multirow[t]{2}{*}{$\mathrm{D}$} & $131.1 \pm 92.3$ & $79.0 \pm 81.7$ & $* * 66.2 \pm 67.9$ \\
\hline & \multicolumn{3}{|c|}{ Urea $(\mathrm{mg} / \mathrm{dL})$} \\
\hline $\mathrm{R}$ & $1774.1 \pm 807.8$ & $1386.7 \pm 754.2$ & ${ }^{\star} 1301.6 \pm 644.1$ \\
\hline \multirow[t]{2}{*}{$\mathrm{D}$} & $1872.6 \pm 956.4$ & $1176.1 \pm 886.9$ & ${ }^{\star} 852.2 \pm 741.9$ \\
\hline & \multicolumn{3}{|c|}{ Osmolarity $(\mathrm{mOsmol} / \mathrm{L})^{2}$} \\
\hline $\mathrm{R}$ & $663.3 \pm 234.2$ & $641.9 \pm 237.8$ & $* * 612.2 \pm 221.2$ \\
\hline \multirow[t]{2}{*}{$\mathrm{D}$} & $643.8 \pm 204.3$ & $489.3 \pm 240.2$ & $* * 357.5 \pm 226.0$ \\
\hline & \multicolumn{3}{|c|}{ Urinary volume $(\mathrm{mL} / \mathrm{min})^{3}$} \\
\hline $\mathrm{R}$ & $1.82[0.99 ; 2.87]$ & $0.76[0.52 ; 1.20]$ & ${ }^{* * *} 0.27[0.15 ; 0.77]$ \\
\hline $\mathrm{D}$ & $1.52[0.93 ; 2.40]$ & $2,02[0.71 ; 6.08]$ & ${ }^{* * *} 1.53[0.66 ; 3.40]$ \\
\hline
\end{tabular}

${ }^{*} \mathrm{p}<0.05 ;{ }^{* *} \mathrm{p}<0.01 ;{ }^{* * *} \mathrm{p}<0.001 .{ }^{1} \mathrm{n}=29 ;{ }^{2}$ Group R (remifentanil, $\mathrm{n}=14$ ), D (dexmedetomidine, $\mathrm{n}=15$ ); ${ }^{3}$ Median, 1st and 3rd quartile between brackets.

Table 4. Clearances of sodium, potassium, creatinine, urea, osmolar, free water $(\mathrm{mL} / \mathrm{min})$ and fractional sodium excretion (\%) of patients undergoing bariatric surgery in groups $\mathrm{R}$ (remifentanil) and D (dexmedetomidine) before anesthesia (MO), after anesthetic induction (M1) and after surgical incision (M2).

\begin{tabular}{|c|c|c|c|}
\hline Group & M0 & M1 & M2 \\
\hline & & Sodium & \\
\hline $\mathrm{R}(\mathrm{n}=30)$ & $2.0 \pm 1.2$ & $1.0 \pm 0.7$ & $0.6 \pm 0.7$ \\
\hline \multirow[t]{2}{*}{$\mathrm{D}(\mathrm{n}=31)$} & $2.0 \pm 1.5$ & $2.4 \pm 3.8$ & $1.2 \pm 1.5$ \\
\hline & & Potassium & \\
\hline $\mathrm{R}(\mathrm{n}=30)$ & $13.4 \pm 8.1$ & $* * 6.2 \pm 3.91$ & $\star 5.05 \pm 6.22$ \\
\hline \multirow[t]{2}{*}{$\mathrm{D}(\mathrm{n}=31)$} & $15.7 \pm 12.4$ & ${ }^{* *} 12.6 \pm 8.0$ & $\star 8.9 \pm 8.1$ \\
\hline & & Creatinine & \\
\hline $\mathrm{R}(\mathrm{n}=30)$ & $247.6 \pm 117.2$ & ${ }^{\star} 109.6 \pm 75.8$ & $90.7 \pm 82.6$ \\
\hline \multirow[t]{2}{*}{$\mathrm{D}(\mathrm{n}=31)$} & $233.2 \pm 132.1$ & ${ }^{\star} 158.7 \pm 110.0$ & $92.3 \pm 68.3$ \\
\hline & & Urea & \\
\hline $\mathrm{R}(\mathrm{n}=30)$ & $95.3 \pm 43.2$ & $\star * 39.8 \pm 24.4$ & $\star 23.4 \pm 25.61$ \\
\hline \multirow[t]{2}{*}{$\mathrm{D}(\mathrm{n}=31)$} & $99.3 \pm 51.5$ & $\star * 74.4 \pm 43.9$ & $* 38.4 \pm 20.3$ \\
\hline & & Osmolarity & \\
\hline $\mathrm{R}(\mathrm{n}=14)$ & $3.7 \pm 2.0$ & $2.0 \pm 1.0$ & $0.8 \pm 0.6$ \\
\hline \multirow[t]{2}{*}{$\mathrm{D}(\mathrm{n}=15)$} & $3.4 \pm 2.1$ & $4.4 \pm 4.1$ & $1.9 \pm 1.8$ \\
\hline & & Water free ${ }^{1}$ & \\
\hline $\mathrm{R}(\mathrm{n}=14)$ & $1.14[0.96 ; 3.31]$ & $1.06[0.36 ; 1.54]$ & $0.30[0.18 ; 0.46]$ \\
\hline \multirow[t]{2}{*}{$\mathrm{D}(\mathrm{n}=15)$} & $1.14[0.34 ; 2.74]$ & $0.90[-0.98 ; 1.36]$ & $0.23[-3.21 ; 0.56]$ \\
\hline & & Excretion of sodium & \\
\hline $\mathrm{R}(\mathrm{n}=30)$ & $0.71[0.41 ; 1.4]$ & $0.89[0.54 ; 1.6]$ & $0.67[0.32 ; 1.12]$ \\
\hline $\mathrm{D}(\mathrm{n}=31)$ & $0.74[0.44 ; 1.3]$ & $0.96[0.57 ; 2.23]$ & $0.81[0.4 ; 2.1]$ \\
\hline
\end{tabular}

${ }^{\star} \mathrm{p}<0.05 ;{ }^{* *} \mathrm{p}<0.001 .{ }^{1}$ Median, 10 and 30 quartile between brackets. 


\section{Discussion}

In the present study, the effect of dexmedetomidine (group D) and remifentanil (group R) on the renal function of morbidly obese patients undergoing bariatric surgery was studied. In group R, from M0-control (before induction of anesthesia) to M1 (after anesthetic induction) and from M1 to M2 (after surgical incision), there was a reduction in mean clearance values in all variables, indicating that the renal function of obese patient had a physiological response compatible with the effect of anesthetic-surgical stress. In group D, the mean values of sodium and osmolar clearance increased from M0 to M1, suggesting better preservation of renal function in this phase of bariatric surgery. In addition, creatinine clearance in M1 and urinary volume in M2 indicated better initial glomerular and distal tubular function in this group, respectively.

Regarding the age group, there was no significant difference between groups. However, according to Sharma et al. [21], patients over 50 years of age are 5 times more at risk of developing acute renal failure than young individuals, because, with advancing age, there is a decline in the glomerular filtration rate.

In this study, real weight was used in the calculation of remifentanil. Egan et al. [22] recommended ideal weight for the use of remifentanil in patients with obesity. However, it is worth adding the practice facility of using the dose used of $0.1 \mu \mathrm{g} \cdot \mathrm{kg}^{-1} \cdot \mathrm{min}^{-1}$ (which was obtained after several simulations, when it was concluded that this dose is very close to that obtained by ideal weight formulas). In addition, the use of dexmedetomidine was done in real weight and, since it is a covert study, remifentanil would also have to be used based on real weight. With regard to dexmedetomidine, there are no studies on pharmacokinetics in obese individuals, using the real weight calculation based on the pharmacodynamic effects observed in our service.

A higher plasma potassium concentration was found in group D in M1 compared to group R. One of the factors that may have contributed to this higher concentration includes the patient's poor positioning on the operating table, which, according to Lagandre et al. [23] represents the cause of rhabdomyolysis in obese people, causing points of greater pressure and consequent cell damage with the release of intracellular content.

In this investigation, there was a higher plasma glucose concentration in M1 and M2 in group D compared to the group R. Belleville et al. [24] found hyperglycemia after administration of dexmedetomidine in volunteers. Blood glucose can be the result of the action of several stress-related hormones (adrenaline, norepinephrine, cortisol, and others) and insulin. In this series, glycemia resulted from the ability of anesthetics dexmedetomidine and remifentanil to block the stress response and dexmedetomidine to inhibit insulin secretion in the pancreas [24]. Fagerholm et al. [25] defined, in a study in rats, the role of the alpha 2a subtype in inhibiting the release of insulin by $\beta$ cells of the pancreas and the consequent hyperglycemia and action of dexmedetomidine in this process.

The plasma concentration of antidiuretic hormone $(\mathrm{ADH})$ did not differ be- 
tween groups. It is known that alpha2 agonist drugs promote increased diuresis [26]. This increase may be due to the inhibition of $\mathrm{ADH}$ secretion [27] or a decrease in its tubular action [28]. In experimental studies, alpha2 receptors have been identified in areas of the kidney [29]. Rouch et al. [30] identified prostaglandin E2 in rats as the second messenger in the mechanism responsible for inhibiting $\mathrm{ADH}$ in the medullary collecting duct. The mechanisms related to $\mathrm{ADH}$ inhibition may be related to hemodynamic factors, such as increased blood pressure [30] and central venous pressure [31] or central block of supraoptic secretory cells [32]. Nascimento et al. [12] observed in the dog that dexmedetomidine inhibited $\mathrm{ADH}$ secretion in a dose-dependent manner, suggesting direct central inhibition of the drug.

In this study, there was no reduction in $\mathrm{ADH}$, probably due to the action of several mechanisms that increase $\mathrm{ADH}$ in response to anesthetic-surgical stress, preoperative fasting, and ventilation with intermittent positive pressure associated with positive end-expiratory pressure. In addition, it is worth mentioning that, in the present study, there was no control group.

In addition, intraoperative remifentanil is associated with increased postoperative analgesic needs and consumption of opioids [1]. Dexmedetomidine has characteristics suggesting that it can replace intraoperative remifentanil during general anesthesia, but the existing literature has reported conflicting results. Thus, a meta-analysis study was conducted to investigate whether general anesthesia, including dexmedetomidine, would result in less postoperative pain than general anesthesia, including remifentanil. Twenty-one randomized controlled trials, including 1309 patients, were identified. Pain scores at rest in two postoperative hours were lower in the dexmedetomidine group, with a mean difference (95\% CI) of $-0.7(-1.2$ to -0.2$), \mathrm{I} 2=85 \%, \mathrm{p}=0.004$ and moderate quality of evidence. Secondary pain results were also significantly better in the dexmedetomidine group. The rates of hypotension, tremors and nausea and vomiting in the postoperative period were at least twice as frequent in patients who received remifentanil. The time to request analgesia was longer, and the use of postoperative morphine and rescue analgesia was shorter, with dexmedetomidine, while episodes of bradycardia were similar between groups. There is moderate evidence that intraoperative dexmedetomidine during general anesthesia improves pain results during the first 24 hours after surgery when compared to remifentanil, with fewer side effects [1].

Before analyzing the results obtained from the clearances, it should be noted that obesity acts on the kidney in order to conserve water and sodium, with an increase in circulating plasma volume at the expense of renal water retention. In the pathophysiology of obesity-related glomerulopathy, mechanisms have proposed that point in this direction. Extrinsic compression of the kidney by visceral fat causes an increase in medullary interstitial hydrostatic pressure and, consequently, compression of the Henle loop and straight vasa, slowing the flow in the renal tubule and straight vasa, favoring the elevation of tubular sodium reabsorption and consequent volume expansion [33]. 
Hormonal factors are also postulated. Leptin secreted by adipocytes can activate the renin-angiotensin-aldosterone system and the sympathetic nervous system [34]. Insulin resistance, associated with visceral obesity, can affect blood pressure by activating the sympathetic nervous system and cause increased sodium reabsorption, as well as blocking the vasodilator response of nitric oxide [35]. Despite several renal changes, few studies have attempted to study renal function in the perioperative period of bariatric surgery.

In this study, there was a gradual worsening of renal function in both groups, most clearly from M0-control (before induction of anesthesia) to M2 (after surgical incision) and from M1 (after anesthetic induction) to M2. The preservation of renal function in obese patients is faced with neurohumor responses in the opposite direction (release of renin, $\mathrm{ADH}$, adrenaline, noradrenaline) in the face of anesthetic-surgical stress and fluid restriction imposed by preoperative fasting. Nguyen et al., [36] investigating hormonal response in morbidly obese patients (BMI 40 - 60) undergoing laparoscopic or open technique gastroplasty, found no significant difference in hormonal response (aldosterone, renin, antidiuretic hormone) after 2 hours gastroplasty. On the other hand, Ortega et al. [37], in non-obese individuals referred for cholecystectomy, found, after 1 hour of surgery, a higher plasma ADH concentration in the group submitted to laparoscopy in relation to the open technique group.

Regarding preoperative fasting, there was no intravenous fluid replacement before the patient was taken to the operating room, as obese patients have difficulty in venoclysis. Thus, fasting was replaced after venipuncture in the operating room and beginning of surgery up to M2.

In this research, despite the similar evolution in both groups due to the absence of adequate blocking of the neuro-endocrine response aiming at protecting the kidney, in group D there were moments with better renal preservation, such as an increase in the mean values of sodium and osmolar clearances from M0 to M1, contrary to the results obtained in group R, in which there was a reduction. In addition, in M1, there was an increase in creatinine and urea clearances in group D compared to group $\mathrm{R}$.

Creatinine clearance corresponds to the measurement of the glomerular filtration rate, indicating proximal function of the kidney. This rate is directly related to the renal flow that is maintained by systemic blood pressure, being directly influenced by the neurohumoral discharge in the face of stress. Frumento et al. [13] found greater creatinine clearance in the group that used epidural dexmedetomidine compared to the control group, in the use for post-thoracotomy analgesia. The authors attributed this result to blocking the neuroendocrine response to stress [38], minimizing the systemic vasoconstrictor response [38], as well as decreasing the release of norepinephrine by presynaptic receptors located in the kidney [39]. Urea clearance can be used as a measure of the glomerular filtration rate. However, this measure is not used, as urea presents tubular reabsorption [40]. 
Potassium clearance in M1 and M2 was higher in group D compared to group $\mathrm{R}$, probably due to the higher plasma concentration of this ion in the first group, since potassium secretion in the final portion of the distal tubules and cortical collecting tubules is directly stimulated by the concentration of increased potassium in the extracellular fluid [41].

Urinary volume was relatively higher in group $\mathrm{D}$ compared to group $\mathrm{R}$, indicating blockade of $\mathrm{ADH}$ tubular action by dexmedetomidine. This can be explained by the non-reduction in plasma concentration by this drug. In addition, in group $\mathrm{D}$ there was a reduction in urinary osmolarity and an increase in plasma osmolarity.

Considering that obese individuals with renal failure represent a challenge for the anesthesiologist, research on the effect of the anesthetics studied here on the hormonal response and consequent renal function in the perioperative period is necessary, as studies show the occurrence of post-gastroplasty renal failure and indicate factors of risk such as BMI > 50 [21], previous chronic kidney disease [21], elevated surgical time [21], intraoperative hypotension [21] [42], hyperlipidemia [32], preoperative use of converting enzyme blocker or blocker angiotensin receptor [42]. Finally, research evaluating the incidence of acute renal failure, in the postoperative period and in a large number of patients undergoing non-cardiac surgery, found nine independent risk factors and one of these was the body mass index (BMI) greater than 32 [43]. This shows the relevance of the present study.

\section{Limitations}

The main limitations that can be pointed out in the present study are the sample size of 61 patients and the fact that hyperglycemia occurs in the dexmedetomidine group.

\section{Conclusion}

In both groups, there was a reduction in the values of clearances from M0 (before anesthesia) to M2 (after surgical incision), indicating that the renal function of the obese patient undergoing bariatric surgery showed a physiological response compatible with the effect of anesthetic-surgical stress. In the remifentanil (R) group, there was a reduction in all clearances in M1 (after anesthetic induction), indicating a response compatible with anesthetic-surgical stress. There was hyperglycemia in the dexmedetomidine group (D). In the dexmedetomidine group (D), there was an increase in creatinine and sodium clearances in M1. The urine volume increased by M2. These results are suggestive of better preservation of renal function.

\section{Funding}

We would like to thank financial support of Base Hospital and Famerp of São José do Rio Preto/SP. 


\section{Conflicts of Interest}

The authors declare no conflicts of interest regarding the publication of this paper.

\section{References}

[1] Grape, S., Kirkham, K.R., Frauenknecht, J. and Albrecht, E. (2019) Intra-Operative Analgesia with Remifentanil vs. Dexmedetomidine: A Systematic Review and Meta-Analysis with Trial Sequential Analysis. Anaesthesia, 74, 793-800. https://doi.org/10.1111/anae.14657

[2] Pan, J., Li, X., He, Y., Jian, C., Chen, H.X., Hei, Z. and Zhou, S. (2018) Comparison of Dexmedetomidine vs. Remifentanil Combined with Sevoflurane during Radiofrequency Ablation of Hepatocellular Carcinoma: A Randomized Controlled Trial. Clinical Journal of Pain, 34, 155-161.

[3] Gao, Y., Deng, X., Yuan, H., Leng, Y., Zhang, T., Xu, X., Tian, S., Fang, J., Ouyang, W. and $\mathrm{Wu}, \mathrm{X}$. (2019) Patient-Controlled Intravenous Analgesia with Combination of Dexmedetomidine and Sufentanil on Patients after Abdominal Operation: A Prospective, Randomized, Controlled, Blinded, Multicenter Clinical Study. Trials, 20, 28.

[4] Zhou, W., Zhang, D., Tian, S., Tan, C., Ma, R., Zhang, J., Sun, J. and Zhang, Z. (2020) Optimal Dose of Dexmedetomidine for Perioperative Blood Glucose Regulation in Non-Diabetic Patients Undergoing Gastrointestinal Malignant Tumor Resection: A Randomized Double-Blinded Controlled Trial. Journal of Investigative Surgery, 1-6. https://doi.org/10.1080/08941939.2019.1706673

[5] Videira, R.L.R. and Cruz, J.R.S. (2004) Remifentanil na prática clínica. Revista Brasileira de Anestesiologia, 54, 114-128. https://doi.org/10.1590/S0034-70942004000100016

[6] Breen, D., Wilmer, A., Bodenham, A., Bach, V., Bonde, J., Kessler, P., et al. (2004) Offset of Pharmacodynamic Effects and Safety of Remifentanil in Intensive Care Unit Patients with Various Degrees of Renal Impairment. Critical Care, 8, R21-R30. https://doi.org/10.1186/cc2399

[7] Dick, J.B. and Shafer, S.L. (1993) Dexmedetomidine Pharmacokinetics and Pharmacodynamics. Anaesthetic Pharmacology Review, 1, 238-245.

[8] Nayashi, Y. and Maze, M. (1993) Alpha 2 Adrenoceptor Agonists and Anaesthesia. British Journal of Anaesthesia, 71, 108-118. https://doi.org/10.1093/bja/71.1.108

[9] Groeben, H., Mitzner, W. and Brown, R.H. (2004) Effects of the Alfa2-Adrenoceptor Agonist Dexmedetomidine on Bronchoconstriction in Dogs. Anesthesiology, 100, 359-363. https://doi.org/10.1097/00000542-200402000-00026

[10] Aantaa, R., Jaakola, M.L., Kallio, A. and Kanto, J. (1997) Reduction of the Minimum Alveolar Concentration of Isoflurane by Dexmetedomidine. Anesthesiology, 86, 1055-1060. https://doi.org/10.1097/00000542-199705000-00008

[11] Kamibayashi, T. and Maze, M. (2000) Clinical Uses of Alpha ${ }_{2}$ Adrenergic Agonists. Anesthesiology, 93, 1345-1349. https://doi.org/10.1097/00000542-200011000-00030

[12] Nascimento, P.V.N., Carvalho, L.R. and Teixeira, A.B. (2003) Renal Effects of Dexmedetomidine, Experimental Study in Dogs. Anesthesiology, A502, 99.

[13] Frumento, R.J., Logginidou, H.G., Wahlander, S., Wagener, G., Playford, H.R. and Sladen, R.N. (2006) Dexmedetomidine Infusion Is Associated with Enhanced Renal Function after Thoracic Surgery. Journal of Clinical Anesthesia, 18, 422-426. https://doi.org/10.1016/j.jclinane.2006.02.005 
[14] Sudré, E.C.M., Salvador, M.C., Bruno, G.E., Vassallo, D.V., Lauretti, G.R. and Sudré Filho, G.N. (2004) Remifentanil versus Dexmedetomidina como coadjuvantes de técnica anestésica padronizada em pacientes com obesidade mórbida. Revista Brasileira de Anestesiologia, 54, 178-179. https://doi.org/10.1590/S0034-70942004000200005

[15] Soto, F.C., Higa-Sansone, G., Copley, J.B., Berho, M., Kennedy, C., LoMenzo, E., et al. (2005) Renal Failure, Glomerulonephritis and Morbid Obesity: Improvement after Rapid Weight Loss Following Laparoscopic Gastric Bypass. Obesity Surgery, 15, 137-140. https://doi.org/10.1381/0960892052993413

[16] Agnani, S., Vachharajani, V.T., Gupta, R., Atray, N.K. and Vachharajani, T.J. (2005) Does Treating Obesity Stabilize Chronic Kidney Disease? BMC Nephrology, 6, 7. https://doi.org/10.1186/1471-2369-6-7

[17] The American Society of Anesthesiologists (ASA) (1998) Relative Value Guide. ASA, Park Ridge, IL.

[18] Benseñor, F.E.M. and Auler Jr., J.O.C. (2004) PETCO2 e $\mathrm{SpO}_{2}$ permitem ajuste ventilatório adequado em pacientes obesos mórbidos. Revista Brasileira de Anestesiologia, 54, 542-552. https://doi.org/10.1590/S0034-70942004000400010

[19] Pelosi, P., Ravagnan, I., Giurati, G., Panigada, M., Bottino, N., Tredici, S., et al. (1999) Positive End-Expiratory Pressure Improves Respiratory Function in Obese But Not in Normal Subjects during Anesthesia and Paralysis. Anesthesiology, 91, 1221-1231. https://doi.org/10.1097/00000542-199911000-00011

[20] Bland, M. (2000) An Introduction of Medical Statistics. 3rd Edition, Oxford University Press, Oxford.

[21] Sharma, S.K., McCauley, J., Cottam, D., Mattar, S.G., Holover, S., Dallal, R., et al. (2006) Acute Changes in Renal Function after Laparoscopic Gastric Surgery for Morbid Obesity. Surgery for Obesity and Related Diseases, 2, 389-392. https://doi.org/10.1016/j.soard.2006.02.002

[22] Egan, T.D., Huizinga, B., Gupta, S.K., Jaarsma, R.L., Sperry, R.J., Yee, J.B., et al. (1998) Remifentanil Pharmacokinetics in Obese versus Lean Patients. Anesthesiology, 89, 562-573. https://doi.org/10.1097/00000542-199809000-00004

[23] Lagandré, S., Aranalsteen, L., Vallet, B., Robin, E., Jany, T., Onraed, B., et al. (2006) Predictive Factors for Rhabdomyolysis after Bariatric Surgery. Obesity Surgery, 16, 1365-1370. https://doi.org/10.1381/096089206778663643

[24] Belleville, J.P., Ward, D.S., Bloor, B.C. and Maze, M. (1992) Effects of Intravenous Dexmedetomidine in Humans. I. Sedation, Ventilation, and Metabolic Rate. Anesthesiology, 77, 1125-1133. https://doi.org/10.1097/00000542-199212000-00013

[25] Fagerholm, V., Grönroos, T., Marjamäki, P., Viljanen, T., Scheinin, M. and Haaparanta, M. (2004) Altered Glucose Homeostasis in Alpha2A-Adrenoceptor Knockout Mice. European Journal of Pharmacology, 505, 243-252. https://doi.org/10.1016/j.ejphar.2004.10.023

[26] Maze, M. and Tranquilli, W. (1991) Alpha-2 Adrenoceptor Agonists: Defining the Role in Clinical Anesthesia. Anesthesiology, 74, 581-605. https://doi.org/10.1097/00000542-199103000-00029

[27] Reid, I.A., Nolan, P.L., Wolf, J.A. and Keil, L.C. (1979) Supression of Vasopressin Secretion by Clonidine: Effect of Alpha-Adrenoceptor Antagonists. Endocrinology, 104, 1403-1406. https://doi.org/10.1210/endo-104-5-1403

[28] Rouch, A.J. and Kudo, L.H. (2000) Role of PGE2 in Alpha 2-Induced Inhibition of AVP-and cAMP-Stimulated $\mathrm{H}_{2} \mathrm{O}, \mathrm{Na}^{+}$, and Urea Transport in Rat IMCD. American Journal of Physiology: Renal Physiology, 279, F294-F301.

https://doi.org/10.1152/ajprenal.2000.279.2.F294 
[29] Schmitz, J.M., Graham, R.M., Sagalowsky, A. and Pettinger, W.A. (1981) Renal Alpha-1 and Alpha-2 Adrenergic Receptors: Biochemical and Pharmacological Correlations. Journal of Pharmacology and Experimental Therapeutics, 219, 400-406.

[30] Humphreys, M.H., Reid, I.A. and Chou, L.Y. (1975) Suppression of Antidiuretic Hormone Secretion by Clonidine in the Anesthetized Dog. Kidney International, 7, 405-412. https://doi.org/10.1038/ki.1975.58

[31] Barr, J.G. and Kauker, M.L. (1979) Renal Tubular Site and Mechanism of Clonidine-Induced Diuresis in Rats: Clearance and Micropuncture Studies. Journal of Pharmacology and Experimental Therapeutics, 209, 389-395.

[32] Barker, J.L., Crayton, J.W. and Nicoli, R.A. (1971) Noradrenaline and Acetylcholine Responses of Supraoptic Neurosecretory Cells. Journal of Physiology, 218, 19-32. https://doi.org/10.1113/jphysiol.1971.sp009602

[33] Hall, J.E., Kuo, J.J., Silva, A.A., Paula, R.B., Kiu, J. and Tallam, L. (2003) Obesity-Associated Hypertension and Kidney Disease. Current Opinion in Nephrology and Hypertension, 12, 195-200. https://doi.org/10.1097/00041552-200303000-00011

[34] Hall, J.E., Hildebrandt, D.A. and Kou, J. (2001) Obesity Hypertension: Role of Leptin and Sympathetic Nervous Systems. American Journal of Hypertension, 14, 103S-115S. https://doi.org/10.1016/S0895-7061(01)02077-5

[35] Tuck, M.L. (1992) Obesity, the Sympathetic Nervous System, and Essential Hypertension. Hypertension, 19, 67-77. https://doi.org/10.1161/01.HYP.19.1_Suppl.I67

[36] Nguyen, N.T., Perez, R.V., Fleming, N., Rivers, R. and Wolfe, B.M. (2002) Effect of Prolonged Pneumoperitoneum on Intraoperative Urine Output during Laparoscopic Gastric Bypass. Journal of the American College of Surgeons, 195, 476-483. https://doi.org/10.1016/S1072-7515(02)01321-2

[37] Ortega, A.E., Peters, J.H., Incarbone, R., Estrada, L., Ehsan, A., Kwan, Y., et al. (1996) A Prospective Randomized Comparison of the Metabolic and Stress Hormonal Responses of Laparoscopic and Open Cholecystectomy. Journal of the American College of Surgeons, 183, 249-256.

[38] Bloor, B.C., Ward, D.S., Belleville, J.P. and Maze, M. (1992) Effects of Intravenous Dexmedetomidine in Humans. II. Hemodynamic Changes. Anesthesiology, 77, 1134-1142. https://doi.org/10.1097/00000542-199212000-00014

[39] Taoda, M., Adachi, Y.U., Uchihashi, Y., Watanabe, K., Satoh, T. and Vizi, E.S. (2001) Effect of Dexmedetomidine on the Release of $\left[{ }^{3} \mathrm{H}\right]$-Noradrenaline from Rat Kidney Cortex Slices: Characterization of Alpha2-Adrenoceptor. Neurochemistry International, 38, 317-322. https://doi.org/10.1016/S0197-0186(00)00096-6

[40] Bello, C.N. (1986) Anatomia, fisiologia e fisiopatologia do sistema urinário. In: Ortenzi, A.V. and Tardelli, M.A., Eds., Organizadores. Anestesiologia-SAESP, Atheneu, São Paulo, 117-130.

[41] Guyton, A.C. (1998) Mecanismos renais e mecanismos associados para o controle dos líquidos corporais e seus constituintes. In: Fisiologia humana e mecanismos das doenças, 6a Edition, Guanabara, Rio de Janeiro, 213-228.

[42] Thakar, C.V., Kharat, V., Blanck, S. and Leonard, A.C. (2007) Acute Kidney Injury after Gastric Bypass Surgery. Clinical Journal of the American Society of Nephrology, 2, 426-430. https://doi.org/10.2215/CJN.03961106

[43] Kheterpal, S., Tremper, K.K., Englesbe, M.J., O’Reilly, M., Shanks, A.M., Douglas, M., et al. (2007) Predictors of Postoperative Acute Renal Failure after Noncardiac Surgery in Patients with Previously Normal Renal Function. Anesthesiology, 107, 892-902. https://doi.org/10.1097/01.anes.0000290588.29668.38 